Letter to the Editor

Spinal Cord (2002) 40, 489. doi:10.1038/sj.sc.3101356

\section{Prevention of pressure sore caused by indwelling urinary catheters}

We read with interest the article on 'Pressure ulcers: an unusual complication of indwelling urethral catheter' by Nair and associates. ${ }^{1}$ In our clinical practice, we observed that even a suprapubic catheter or drainage tube of a leg bag could cause pressure sores. The ideal solution will be to get rid of indwelling urinary catheters and tubing. This requires establishing a regimen of intermittent catheterisation by antimuscarinic drugs, if needed. Intermittent catheterisation with oxybutynin has helped persons with spinal cord injury to remain continent between catheterisations. ${ }^{2}$ However, intermittent catheterisation may not be feasible in a community set-up due to lack of support. ${ }^{3}$ We were successful in preventing pressure sores caused by indwelling catheters by wrapping the catheter with a soft cloth such as Ultra-Cloth Extra or Conti Super-Soft and then with a silk tape, which holds the former in place (Figure 1). Wrapping a catheter with a non-irritant, soft material is a simple thing to do and this has proved effective towards prevention of catheterinduced pressure sores in persons with spinal cord injury.

\section{Acknowledgement}

The authors wish to record their gratitude to Mr Stephen Ley, Reed-Shilling Healthcare, Southmead Industrial Park, Didcot, Oxfordshire OX11 7HR, UK for kindly sponsoring the printing of colour illustration of this article.

S Vaidyanathan, BM Soni, J Bingley, E Brown, S Markey Regional Spinal Injuries Centre, District General Hospital, Town Lane Southport PR8 6PN, UK

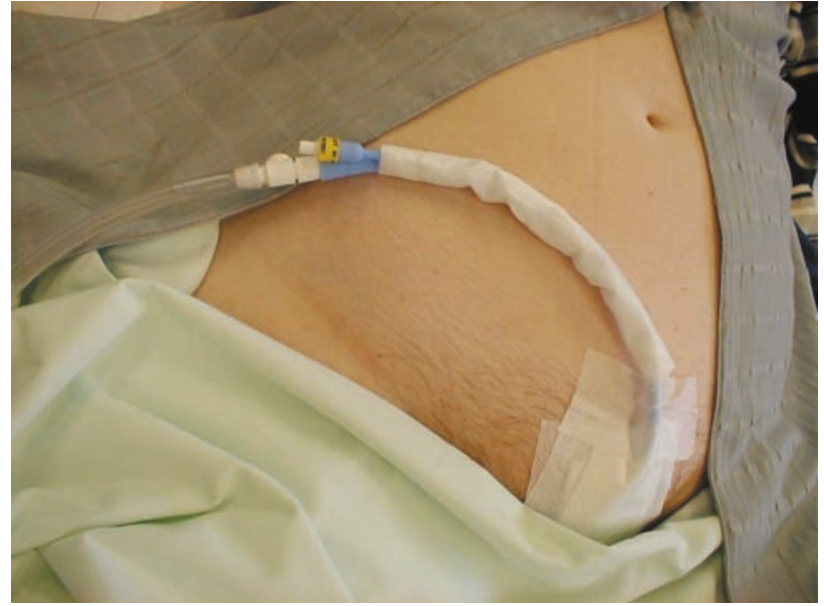

Figure 1 Photograph of a suprapubic catheter in a female with traumatic paraplegia. The suprapubic catheter has been wrapped around with Ultra-Cloth Extra, which is held in place by silk tape. Wrapping a catheter with a non-irritant, soft material has proved effective towards prevention of catheter-induced pressure sores, particularly in persons with spinal cord injury, who easily develop pressure sores at the slightest insult

2 Vaidyanathan $\mathrm{S}$ et al. Effect of intermittent urethral catheterization and oxybutynin bladder instillation on urinary continence status and quality of life in a selected group of spinal cord injury patients with neuropathic bladder dysfunction. Spinal Cord 1998; 36: 409-414.

3 Vaidyanathan $\mathrm{S}$ et al. Community-care Waiting list for persons with Spinal Cord Injury. Spinal Cord 2001; 39: $584-588$.

\title{
References
}

1 Sivaraman Nair KP, Tally AB, Roopa N, Murali T. Pressure ulcers: An unusual complication of indwelling urethral catheter. Spinal Cord 2001; 39: 234-236. 